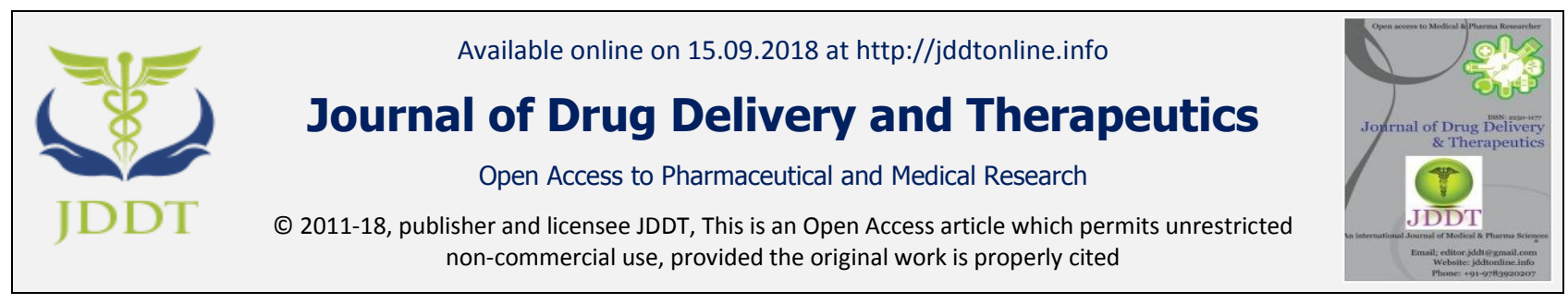

Open $\odot$ Access

Research Article

\title{
FORMULATION AND CHARACTERIZATION OF MICROSPHERES OF NITAZOXANIDE BY CHEMICAL CROSSLINKING METHOD
}

\author{
*Sachan A.K., Gupta A., Kumari K. and Ansari A. \\ Dayanand Dinanath College, Institute of Pharmacy, Kanpur -209214 (INDIA)
}

\begin{abstract}
The work investigated the design and evaluation of microspheres of Nitazoxanide by Ionotropic gelation technique method. $3^{2}$ Factorial designs were used and concentration of polymer carbopol-934 (X1) and Ethyl cellulose (X2) were selected as the independent variables. The surface morphology study by SEM indicated that microspheres were spherical with smooth surface. There was no interaction between the drug and polymers, as studied by FTIR study. The prepared microspheres were characterized by entrapment efficiency, particle size micromeritic properties. It was observed that on increasing polymer concentration of formulations, \% yield, the entrapment efficiency and particle size were increased whereas \% drug release decreased. The In Vitro release study was done using U.S.P. dissolution rate basket type apparatus in phosphate buffer pH 7.4 for $10 \mathrm{hr}$. It shows that on increasing polymer concentration the drug release of all formulations was gradually decreased. In Vitro mucoadhesion study depicts that as the polymer concentration increased, mucoadhesive nature of the formulation was also increased. The microspheres of NTZ (formulation $\mathrm{F}_{9}$ ) showed best results due to highest drug entrapment efficiency (85.50\%), and percentage drug release after 10.0 hr. was $50.25 \%$. The rate of release followed First order kinetics. The microspheres exhibits good mucoadhesive properties in in- vitro wash-off test at $\mathrm{pH} 7.4$ (Intestinal $\mathrm{pH}$ ) than $\mathrm{pH} 1.2$ (gastric $\mathrm{pH}$ ), because the drug was completely absorbed in Gastrointestinal tract, Therefore, it can be concluded that Nitazoxanide Loaded algino-carbopol-934 microspheres can be formulated for sustained drug delivery of Nitazoxanide used in Chronic Hipatitis-C.
\end{abstract}

Keywords: Mucoadhesive microspheres, Nitazoxanide, Carbopol-934, Ethyl cellulose, Sodium Alginate, Factorial design.

Article Info: Received 12 June, 2018; Review Completed 02 Aug 2018; Accepted 07 Aug 2018; Available online 15 Sep 2018

\section{Cite this article as:}

Sachan A.K., Gupta A., Kumari K., Ansari A., Formulation and characterization of microspheres of nitazoxanide by chemical crosslinking method, Journal of Drug Delivery and Therapeutics. 2018; 8(5):190-199 DOI: http://dx.doi.org/10.22270/iddt.v8i5.1850

*Address for Correspondence:

Anupam Kumar Sachan, Dayanand Dinanath College, Institute of Pharmacy, NH\#86, Ramaipur, Kanpur - 209214

\section{INTRODUCTION}

Microspheres are small spherical particles, with diameters in the micrometer range (typically $1 \mu \mathrm{m}$ to $1000 \mu \mathrm{m})$, manufactured from natural or synthetic polymers. Microspheres have numerous applications depending on what material they are constructed of and what size they are. Microsphere play numerous applications in biomedical sciences from diagnostic to drug delivery microsphere had reported for chemoembolisation (endovascular therapy)' radio imaging topical delivery, vaccine delivery and delivery of Monoclonal antibodies mediated microspheres targeting. ${ }^{1-10}$
Nitazoxanide (NTZ) chemically [2-[(5-nitro-1, 3-thiazol2-yl) carbamoyl] phenyl] acetate, which is a newly approved antiprotozoal drug used in the treatment of cryptosporidiosis in immune comprised patients including those with AIDS or HIV infection ${ }^{7-10}$. NTZ is rapidly absorbed and converted to active metabolite tizoxanide, which inhibit Pyruvate ferredoxin oxidoreductase pathway. Nitazoxanide appears to have activity against metronidazole (MTZ) resistant protozoal strains and well tolerated.

It is indicated for amoebiasis, helminthiasis giardiasis, fascioliasis, trichomoniasis and cryptosporidiosis ${ }^{10-14}$. The anti-protozoal activity of nitazoxanide is believed to 
be due to interference with the pyruvate:ferredoxin oxidoreductase (PFOR) enzyme dependent electron transfer reaction which is essential to anaerobic energy metabolism. ${ }^{15-20}$ It has also been shown to have activity against influenza A virus. A survey of literature reveals that very few method \& solvents were available for the estimation of Nitazoxanide.

\section{MATERIALS AND METHODS}

\section{Materials}

Nitazoxanide was obtained from Alembic Pharmaceutical Ltd. Vadodara India. Carbopol-934 was obtained from Manish Pharma, Baddi, India. Sodium alginate, ethyl cellulose, calcium chloride, di sodium hydrogen phosphate, and methanol were obtain from $\mathrm{S}$ .D. Fine chemicals. All the other chemicals and reagents were of analytical grade. Drug and polymer were evaluated spectometrically for purity, identity.

\section{Method}

In brief weight quantity of sodium alginate $(3 \%)$ and ethyl cellulose were dissolved separately in distilled water $(100 \mathrm{~mL})$ and ethanol $(5 \mathrm{~mL})$. Then solution of ethanol was mixed in previously prepared sodium alginate solution. In separate beaker weight quantity of drug and Corbopol- 934 were dissolved in methanol and added to above solution with continuous stirring. The prepared mixture was dropped into $\mathrm{CaCl}_{2}(3 \%$ w/v) solution using $26 \mathrm{G}$ Syringe needle. Microspheres were obtained, filtered, washed with distilled water, air-dried at room temperature and stored in desiccators. ${ }^{20-27}$

\section{Formulation Design}

Table 1: $3^{2}$ full factorial design, 2-factor, 3-level.

\begin{tabular}{|c|c|c|c|c|c|}
\hline F.code & Drug (mg) & $\begin{array}{c}\text { EC (mg) } \\
\left(\mathrm{X}_{1}\right)\end{array}$ & $\begin{array}{c}\text { CP (mg) } \\
\left(\mathbf{X}_{2}\right)\end{array}$ & $\begin{array}{c}\text { Sodium Alginate } \\
\% \mathrm{w} / \mathrm{v}\end{array}$ & $\begin{array}{c}\text { Crosslinking agent } \mathrm{CaCl}_{2} \\
\% \mathrm{w} / \mathrm{v}\end{array}$ \\
\hline F1 & 30 & 60 & 60 & 3 & 3 \\
\hline $\mathrm{F} 2$ & 30 & 30 & 60 & 3 & 3 \\
\hline F3 & 30 & 90 & 60 & 3 & 3 \\
\hline $\mathrm{F} 4$ & 30 & 60 & 30 & 3 & 3 \\
\hline F5 & 30 & 30 & 30 & 3 & 3 \\
\hline F6 & 30 & 90 & 30 & 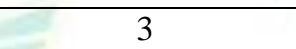 & $\sqrt{2}$ \\
\hline F7 & 30 & 60 & 90 & 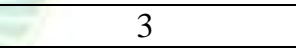 & 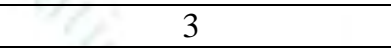 \\
\hline F8 & 30 & 30 & 90 & 3 & 3 \\
\hline F9 & 30 & 90 & 90 & 3 & 3 \\
\hline
\end{tabular}

\section{Particle size}

Particle size of Nitazoxanide microspheres were measured by optical microscopy. The values obtained were from triplicate experiments and expressed as mean \pm standard deviation ${ }^{28-31}$.

Microsphere recovery, drug content and entrapment efficiency

Nitazoxanide Microsphere recovery (\%) was calculated by weighing lyophilized Microsphere accurately, and using following formula

$$
\text { Microsphere Recovery }=\frac{\text { Wt of microspheres }}{\text { Wt of drug and polymer }} \times 100
$$

\section{Drug content study}

The drug content of microsphere was determined by spectrophotometrically at $414.4 \mathrm{~nm}$ (UV-2201, $\underset{32-35}{\text { Systonics). Each determination was made in triplicate. }}$

Drug content were calculated by using following formula

$$
\text { Drug Content }=\text { Conc. } \times \text { dilution factor } \times \text { volume } / 1000
$$

\section{Morphological Examination (SEM)}

A texture of surface for prepared microspheres was done by taking Scanning electron photomicrographs. The sample was spread on stub and coated for 120 Swith a layer of gold using a sputter coater. Afterwards, the stub containing the sample was placed in the scanning electron microscope (ZEISS) chamber at the acceleration voltage of $10 \mathrm{kV}$, chamber pressure of 0.6 mm Hg. ${ }^{36-39}$

\section{X-ray Powder Diffractometry (XRD)}

Diffraction patterns of physical mixtures; drug and polymers were recorded with a PW 3040/60 X' Pert PRO, Netherland. A voltage of $40 \mathrm{KV}$ and a current of $45 \mathrm{~mA}$ for the generator were used, with $\mathrm{Cu}$ as the tube anode material. The solids were exposed to $\mathrm{Cu}-\mathrm{K} \alpha$ radiation $(\alpha 1=1.54060 \AA$ and $\alpha 2=1.54439 \AA$, with a $\alpha 1 / \alpha 2$ ratio of 0.5 ), over a range of $2 \theta$ angles from $0^{\circ} \mathrm{C}$ to $60^{\circ} \mathrm{C}$, at an angular speed of $3^{0}(2 \theta)$ per minute.

\section{Differential scanning calorimetry (DSC)}

DSC provides information about all physical properties of sample as Crystalline or Amorphous nature and demonstrates the possible interaction between Drug and other Polymers. ${ }^{40}$

\section{In-vitro mucoadhesion study}

The mucoadhesive property of microspheres was evaluated by an in vitro adhesion testing method known as wash-off method by using freshly excised piece of intestinal mucosa $(2 \times 2 \mathrm{~cm})$ from goat, glass slides $(3 \times$ 1 inch) and USP tablet disintegrating test machine ${ }^{41-43}$. In brief microsphere were spread on tissue specimen attached with glass slide and hung it on to the arm of USP apparatus then assembly started. At the end of one 


\section{Sachan et al}

hour no of number of microspheres still adhering to tissue was calculated as following.

$\%$ mucoadhesion $=\frac{\text { weight of adhered microspheres }}{\text { weight of applied microspheres }} \times 100$

\section{In-vitro drug distribution study}

In-vitro drug distribution study of Nitazoxanide microsphere were calculated spectometrically by using basket dissolution apparatus ${ }^{44-50}$.

\section{Stability of Mucoadhessive microspheres}

Stability studies were performed according to ICH and WHO guidelines. Optimized microspheres were packed in an aluminum foil and kept in petridish at room temperature $\left(37^{\circ} \mathrm{C}\right)$ and in Humidity chamber at $40^{\circ} \mathrm{C}$, $75 \% \mathrm{RH}$ for a period of 28 days $^{51-55}$. At the end of studies, Microspheres were evaluated for physical properties, in-vitro drug release and drug content.

\section{RESULTS AND DISCUSSION}

\section{Drug Identification Tests}

Journal of Drug Delivery \& Therapeutics. 2018; 8(5):190-199

\section{Melting Point Determination (Capillary Method)}

Melting point of the drug was determined using capillary method by the melting point apparatus. Drug was filled in the capillary after sealing the capillary from one end and then the sample was placed in the apparatus along with the thermometer and when the drug melted its temperature is recorded. Melting point of the drug sample was found to be $198^{\circ} \mathrm{C}$ (Ideal m.p. $202^{\circ} \mathrm{C}$ ).

\section{UV Spectrophotometric Study}

The $\lambda_{\max }$ was determined by preparing the $25 \mathrm{ml}$ Actonitrile \& water (9:1) solution of $2 \mu \mathrm{g} / \mathrm{ml}-10 \mu \mathrm{g} / \mathrm{ml}$ and further the sample was scanned at the range of 400$200 \mathrm{~nm}$. It was observed that the maximum absorbance was seen at 238.3nm, (using UV2201Pharma Spec Systronics) which was regarded as the $\lambda_{\max }$ of the drug Nitazoxanide. The $\lambda_{\max }$ of the drug Nitazoxanide in 50 $\mathrm{ml}$ Methanol:water (50:50) mixture was found to be $328 \mathrm{~nm}$ as \& in $\mathrm{pH} 7.4$ phosphate buffer was found to be $414.4 \mathrm{~nm}$.

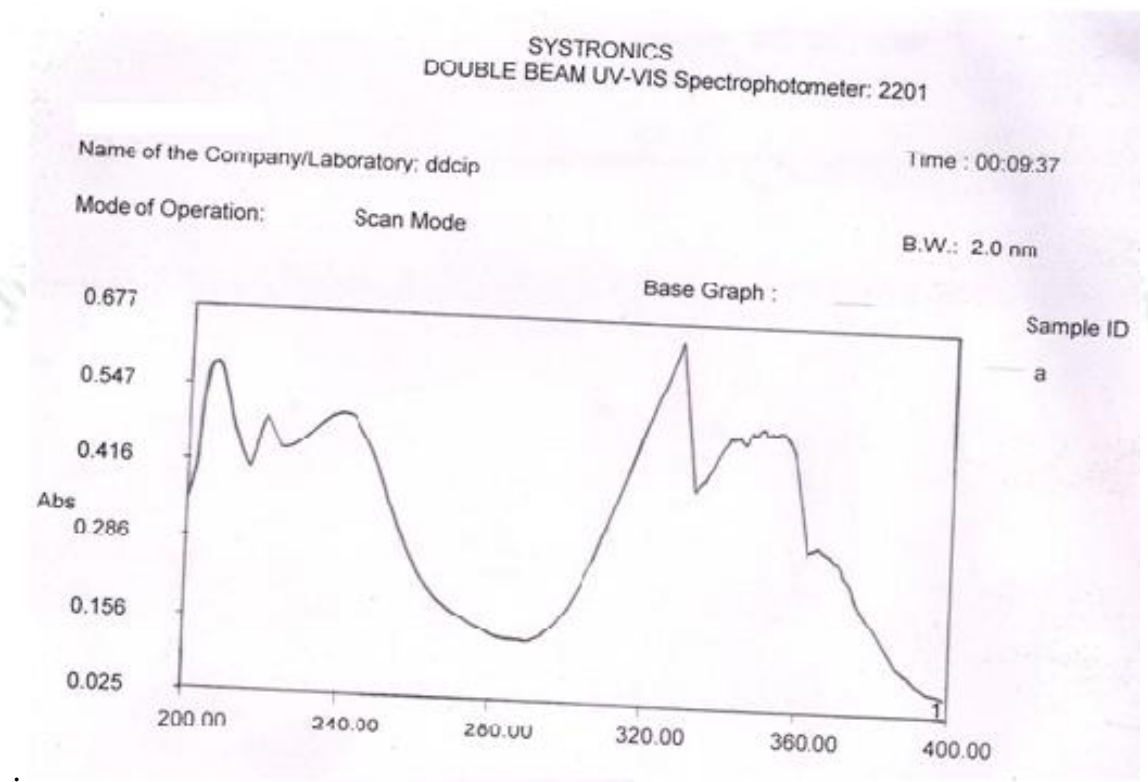

Figure 1: $\lambda_{\max }$ Scan for the drug at $238.3 \mathrm{~nm}$ in $25 \mathrm{ml}$ Acetonitrile \& water Solution (9:1)

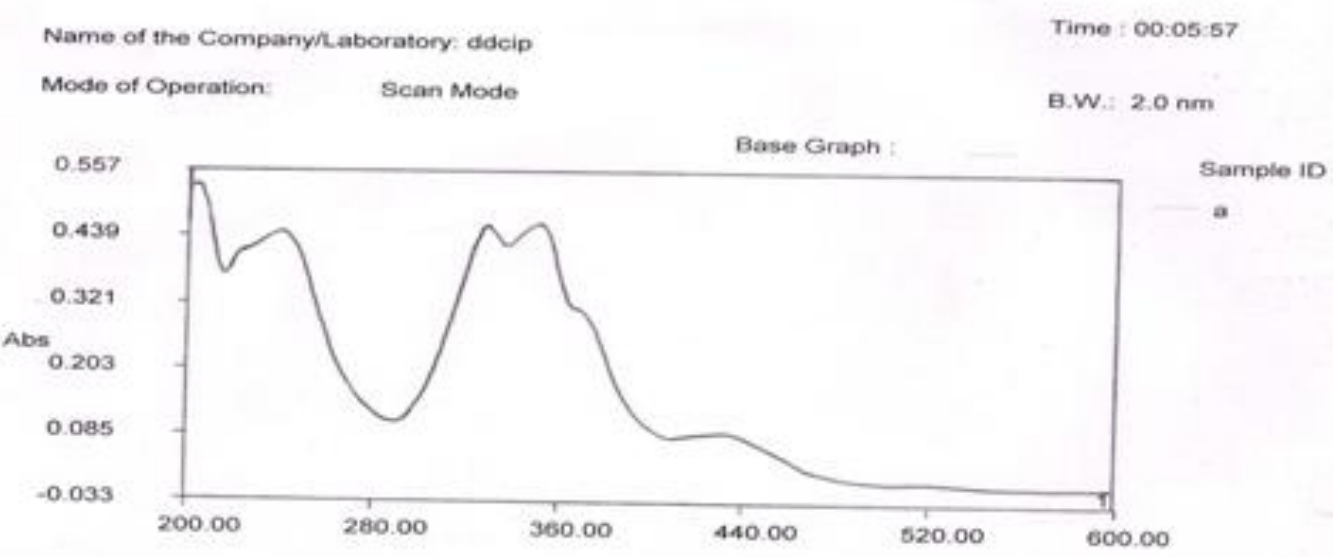

Figure 2: $\lambda_{\max }$ Scan for the drug at $328 \mathrm{~nm}$ in methanol:water (50:50) mixture 
SYSTRONICS

DOUBLE BEAM UV-VIS Spectrophotometer: 2201

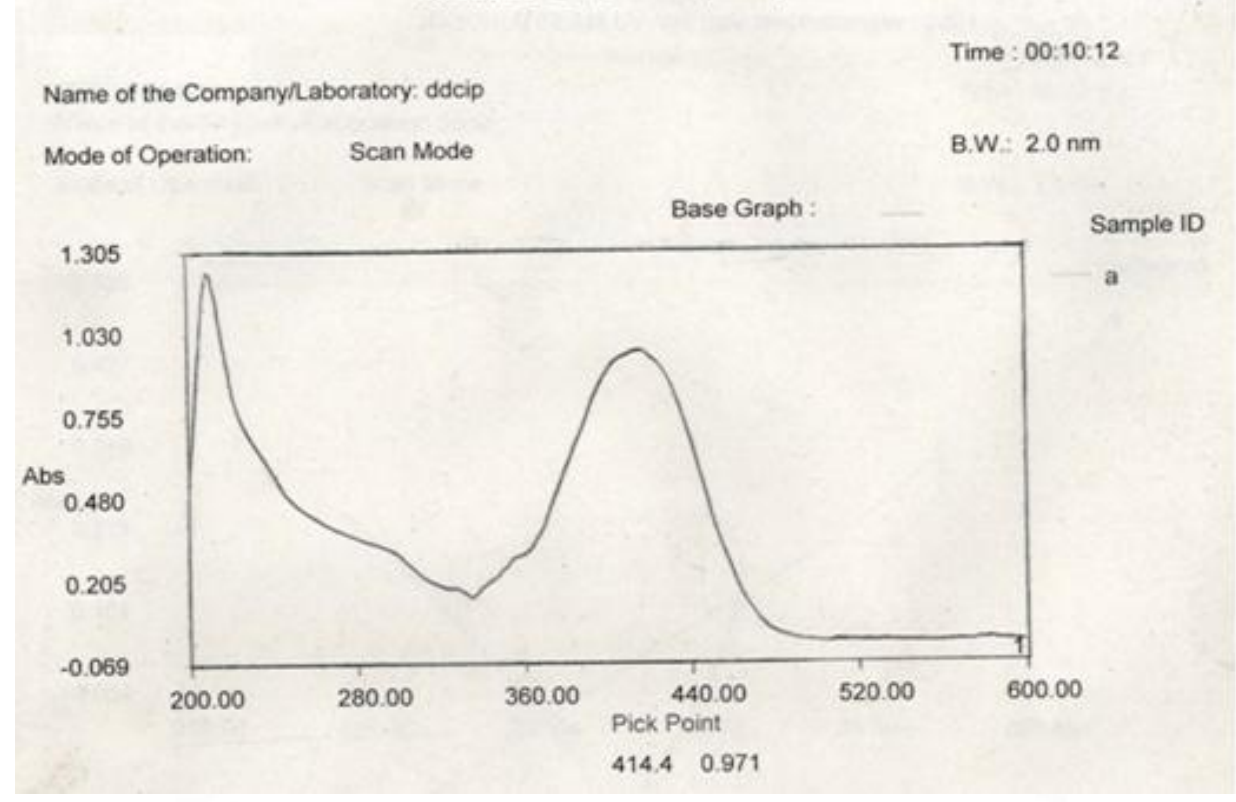

Figure 3: $\lambda_{\max }$ Scan for the drug at $414.4 \mathrm{~nm}$ in $\mathrm{pH} 7.4$ phosphate buffer Solution

\section{IR Spectral Analysis}

Infrared (IR) spectroscopy was performed using FTIR Spectrophotometer (Shimadzu) the spectrum was recorded in the wavelength region of 4000 to $600 \mathrm{~cm}^{-1}$.
Pellets for the spectra were prepared using $\mathrm{KBr}$ hydraulic press, by dispersing a sample of drug in $\mathrm{KBr}$ and compressed into discs. The pellet was then placed in the FTIR and the spectrum was obtain and its interpretation is shown below.

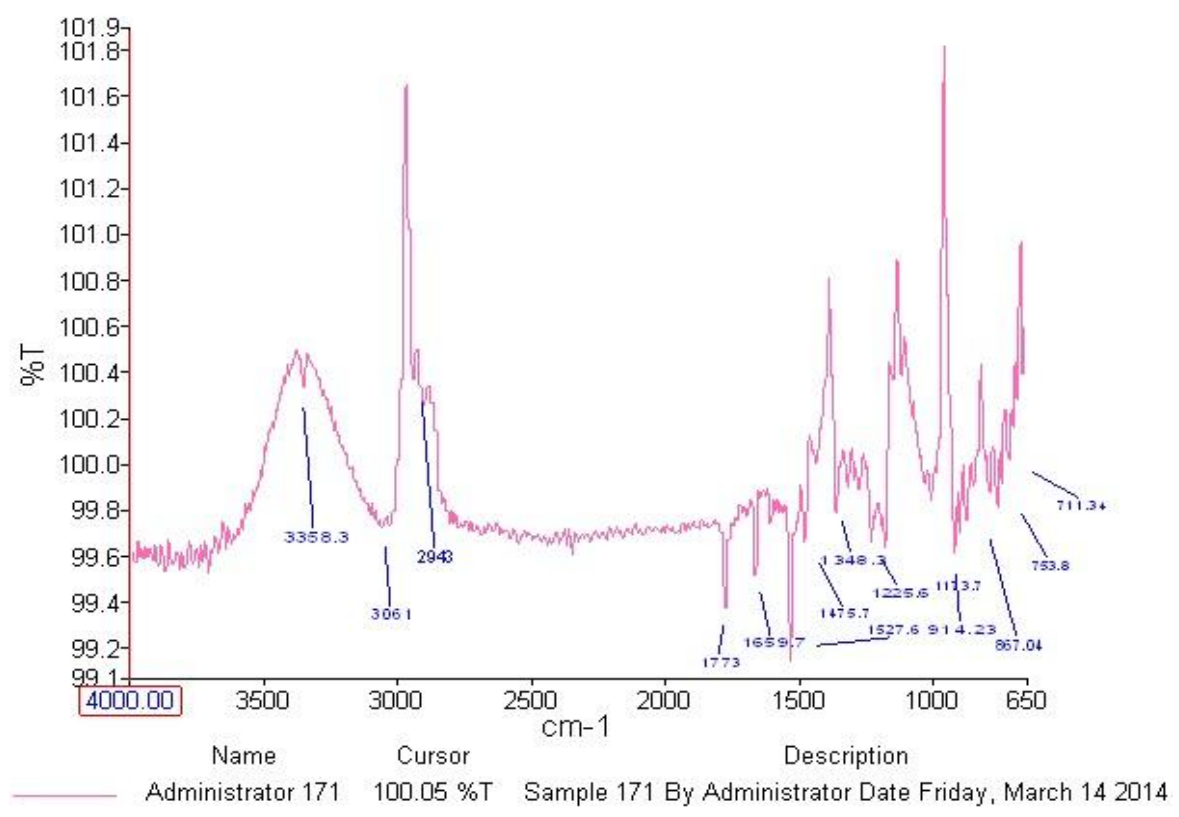

Figure 4: IR spectra of pure drug Nitazoxanide

Table 2: Interpretation of IR spectra of pure drug Nitazoxanide

\begin{tabular}{|c|l|l|l|}
\hline S.No. & Functional Group & Range $\left.\mathbf{( c m}^{-1}\right)$ & Observed Frequency $\left(\mathbf{c m}^{-\mathbf{1}}\right)$ \\
\hline 1 & Carbonyl group- ester linkage amide Linkage & $1690-1760$ & 1773 \\
& & $1700-1680$ & 1659.7 \\
\hline 2 & Nitro group & $1500-1350$ & 1527.69 \\
\hline 3 & =CH stretch & $2960-2850$ & 3061 \\
\hline
\end{tabular}


Compatibility Studies between the Drug and Polymer

For the drug excipients compatibility studies, the sample were kept at $40^{\circ} \mathrm{C} \& 75 \% \mathrm{RH}$ for 4 weeks, sample withdrawn, carried out and evaluated. For the result of compatibility studies that there was no change in physical appearance and optimized formulation, no incompatibility in drug alone or with excipients as same peaks were observe. In IR Spectra of physical mixture \& optimized formulation are compared to Nitazoxanide drug which shows that there were no interaction between drug and polymer as shown in Figure $5 \&$ Figure 6 .

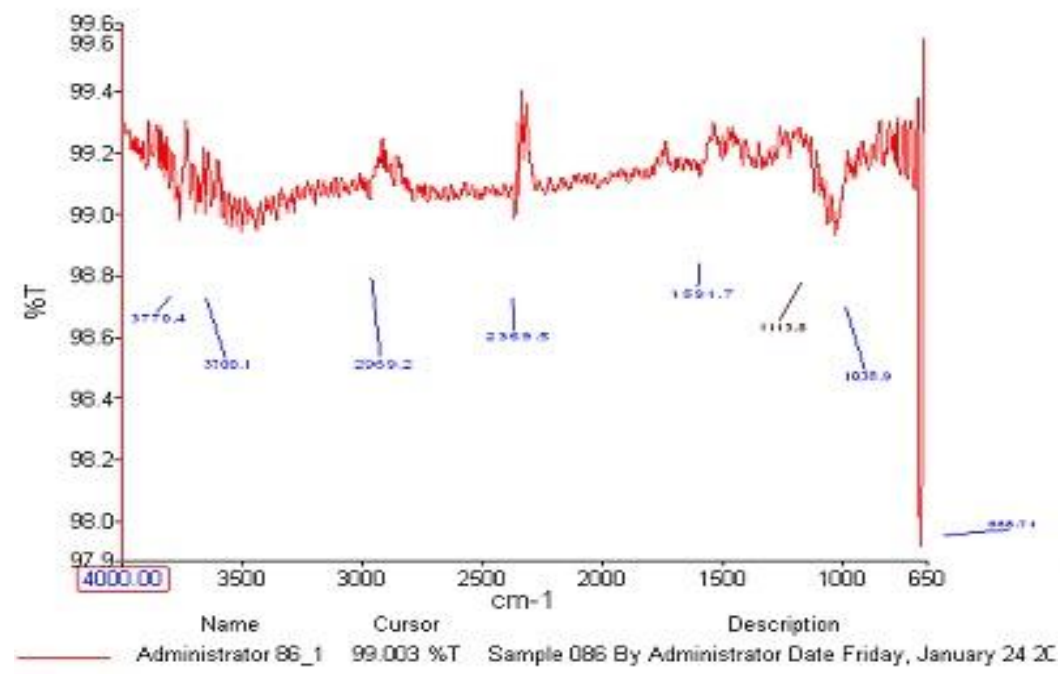

Figure 5:IR spectra of microspheres of Physical mixture of of Drug Nitazoxanide and Polymer carbopol-934

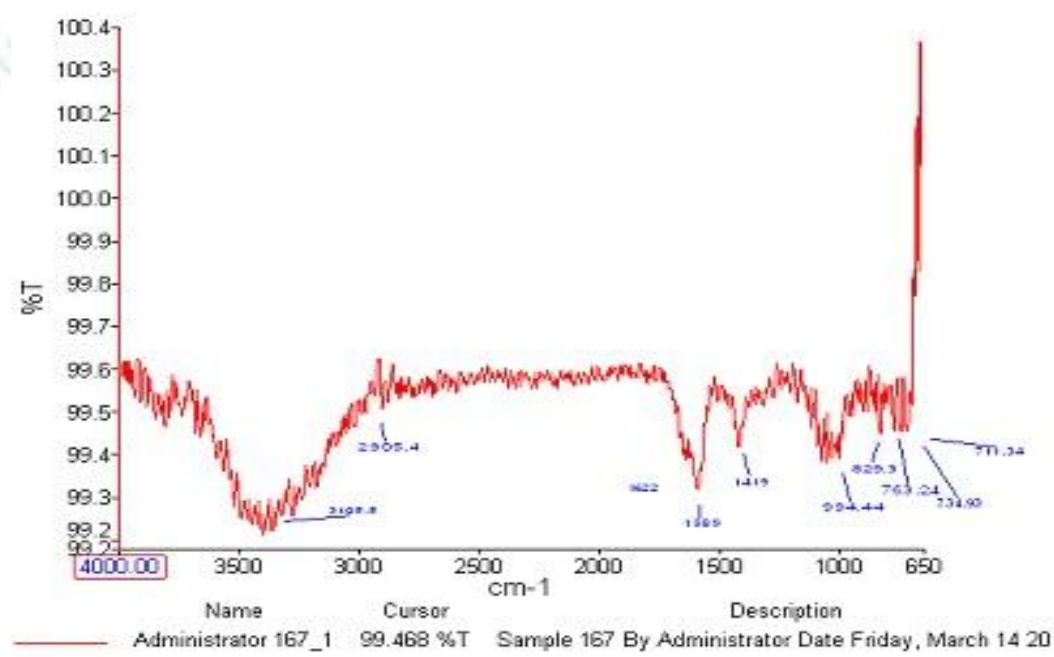

Figure 6 :IR spectra of microspheres of optimized formulation of Nitazoxanide

Table 3: Interpretation of IR spectra of Physical mixture of of Drug Nitazoxanide and IR spectra of microspheres of optimized formulation of Nitazoxanide

\begin{tabular}{|c|c|l|l|}
\hline S.No. & Functional Group & Range $\left(\mathbf{c m}^{-\mathbf{1}}\right)$ & Observed frequency $\left(\mathbf{c m}^{-\mathbf{1}}\right)$ \\
\hline 1 & -OH group & $3000-3700$ & 3700.1 \\
\hline 2 & Carbonyl group & $1690-1760$ & 1720 \\
\hline 3 & Nitro group & $1330-1640$ & 1622 \\
\hline 4 & Amide group & $3000-3700$ & 3405.5 \\
\hline
\end{tabular}

\section{Evaluation of Microspheres}

\section{Micrometric Properties of microspheres}

\section{Particle Size Analysis}

The optical microscopy method was used to determine the particle size of prepared microspheres, in this method, the diameter of 100 microspheres was determined and from it the mean diameter was calculated. All readings were taken in triplicate.

The mean particle size was found to be $580.75 \pm 6.87 \mu \mathrm{m}$ to $729.94 \pm 10.12 \mu \mathrm{m}$ 
Bulk density

The bulk density was found to be $0.320 \pm .03 \mathrm{gm} / \mathrm{cm}^{3}$ to $0.450 \pm .03 \mathrm{gm} / \mathrm{cm}^{3}$

\section{Tapped density}

The tapped density was found to be $0.358 \pm 0.01 \mathrm{gm} / \mathrm{cm}^{3}$ to $0.520 \pm .02 \mathrm{gm} / \mathrm{cm}^{3}$

Table 4: Characterization of mucoadhesive microspheres of Nitazoxanide

\begin{tabular}{|c|l|l|l|l|l|}
\hline F.Code & $\begin{array}{l}\text { BulK } \\
\text { Density }\end{array}$ & $\begin{array}{l}\text { Tapped } \\
\text { density }\end{array}$ & $\begin{array}{l}\text { \%Carr's } \\
\text { index }\end{array}$ & $\begin{array}{l}\text { Hausner's } \\
\text { Ratio }\end{array}$ & $\begin{array}{l}\text { Angle of repose } \\
\boldsymbol{\emptyset}=\mathbf{t a n}^{-1}(\mathbf{h} / \mathbf{r})\end{array}$ \\
\hline F1 & $0.398 \pm 0.01$ & $0.422 \pm 0.02$ & $5.68 \pm 0.10$ & $1.060 \pm 0.01$ & $14.06 \pm 1.20$ \\
\hline F2 & $0.435 \pm 0.02$ & $0.464 \pm 0.02$ & $6.25 \pm 0.15$ & $1.167 \pm 0.01$ & $21.88 \pm 0.15$ \\
\hline F3 & $0.411 \pm 0.01$ & $0.434 \pm 0.02$ & $5.30 \pm 0.12$ & $1.056 \pm 0.01$ & $12.86 \pm 0.14$ \\
\hline F4 & $0.510 \pm 0.03$ & $0.546 \pm 0.03$ & $6.59 \pm 0.09$ & $1.071 \pm 0.02$ & $14.25 \pm 0.15$ \\
\hline F5 & $0.468 \pm 0.02$ & $0.524 \pm 0.12$ & $10.68 \pm 0.07$ & $1.119 \pm 0.03$ & $14.35 \pm 0.15$ \\
\hline F6 & $0.407 \pm 0.02$ & $0.442 \pm 0.13$ & $7.92 \pm 0.13$ & $1.086 \pm 0.02$ & $15.89 \pm 0.19$ \\
\hline F7 & $0.528 \pm 0.03$ & $0.563 \pm 0.12$ & $6.21 \pm 0.12$ & $1.066 \pm 0.02$ & $25.32 \pm 0.11$ \\
\hline F8 & $0.635 \pm 0.03$ & $0.658 \pm 0.13$ & $3.49 \pm 0.13$ & $1.036 \pm 0.09$ & $24.02 \pm 0.14$ \\
\hline F9 & $0.571 \pm 0.02$ & $0.587 \pm .011$ & $2.73 \pm 0.11$ & $1.028 \pm 0.01$ & $20.45 \pm 0.10$ \\
\hline
\end{tabular}

*F5 formulation showed the best flow property and flow of all other formulations were excellent this showed that particles were decreases their crystallinity.

Table 5: Evaluation of mucoadhesive microspheres of Nitazoxanide in $10 \mathrm{hr}$.

\begin{tabular}{|c|c|c|c|c|c|}
\hline F.Code & $\begin{array}{l}\text { \%Yield } \\
\pm \text { S.D. }\end{array}$ & $\begin{array}{l}\text { Theoretical drug } \\
\text { content (mg) }\end{array}$ & $\begin{array}{l}\text { Actual drug content } \\
(\mathrm{mg}) \pm \text { S.D. }\end{array}$ & $\begin{array}{l}\text { \%Drug } \\
\text { entrapment } \pm \text { S.D. }\end{array}$ & $\begin{array}{l}\text { Average particle } \\
\text { size } \pm \text { S.D. }\end{array}$ \\
\hline F1 & $83.55 \pm 1.14$ & 30 & $22.10 \pm 0.71$ & $73.66 \pm 1.67$ & $642.65 \pm 5.41$ \\
\hline $\mathrm{F} 2$ & $80.45 \pm 2.05$ & 30 & $21.28 \pm 0.74$ & $72.66 \pm 2.10$ & $585.45 \pm 4.10$ \\
\hline F3 & $87.22 \pm 2.01$ & 30 & $23.15 \pm 0.68$ & $77.16 \pm 1.96$ & $702.56 \pm 5.69$ \\
\hline $\mathrm{F} 4$ & $81.61 \pm 2.70$ & 30 & $21.65 \pm 0.35$ & $72.16 \pm 1.85$ & $642.7 \pm 5.13$ \\
\hline F5 & $76.19 \pm 1.53$ & 30 & $20.16 \pm 0.25$ & $67.20 \pm 1.04$ & $580.75 \pm 6.87$ \\
\hline F6 & $85.77 \pm 2.93$ & 30 & $22.69 \pm 0.13$ & $75.63 \pm 1.25$ & $680.2 \pm 6.17$ \\
\hline F7 & $87.09 \pm 1.40$ & 30 & $24.46 \pm 0.15$ & $81.53 \pm 1.09$ & $648.85 \pm 5.51$ \\
\hline F8 & $86.88 \pm 1.91$ & 30 & $22.91 \pm 0.08$ & $76.36 \pm 1.64$ & $590.62 \pm 6.40$ \\
\hline F9 & $90.22 \pm 1.51$ & 30 & $25.65 \pm 0.10$ & $85.50 \pm 1.54$ & $729.94 \pm 10.12$ \\
\hline
\end{tabular}

F9 Formulation showed best result due to high \% drug entrapment \& high \% Yield

Because in F9 formulation higher polymer concentration.

\section{SEM}

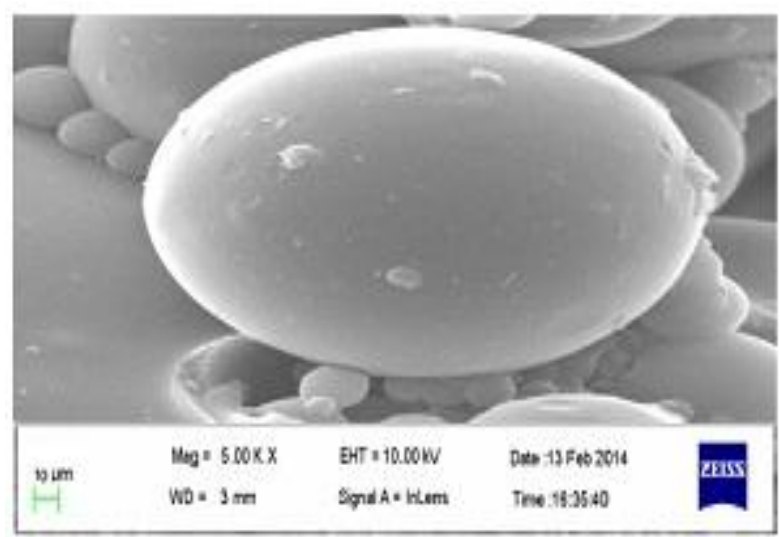

The surface morphology of mucoadhesive microspheres was examined by Scanning electron microscopy (SEM) ,the SEM showed that microspheres obtained from optimized formulation was spherical and smooth surface at two different magnifications $(10 \mu \mathrm{m} \& 50 \mu \mathrm{m})$ as shown in Fig.7.

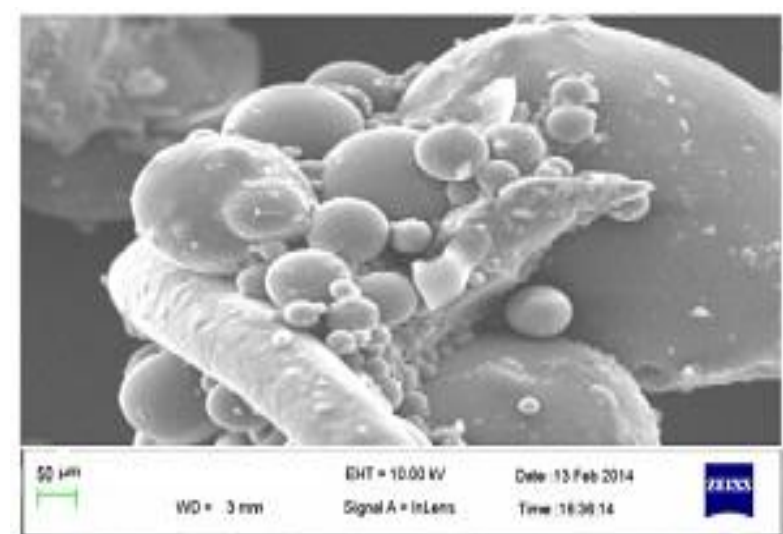

(A): SEM Photograph (10 $\mu \mathrm{m})$ of formulation (F9 (B): SEM Photograph (50 $\mu \mathrm{m})$ of formulation (F9)

Figure 7: SEM micrograph of optimized Formulation of Nitazoxanide microspheres (F9 under two different magnifications (A \& B $10 \mu \mathrm{m} \& 50 \mu \mathrm{m})$. 
Powder X-Ray Diffraction Study (PXRD) of Drug and Formulation

The presence of several Large peaks in the PXRD of Pure drug Nitazoxanide at a diffraction angle of $6.50^{\circ}$, $25.02^{\circ}, 31.50^{\circ}$ and $46.25^{\circ}$ were obtained, but in
Nitazoxanide microspheres formulation small peaks were obtained at diffraction angle $31.53{ }^{\circ}$, $44.84^{\circ} \& 56.85^{\circ}$ were obtained revealed that the drug is present as a crystalline form and converted into amorphous form as shown in figure.

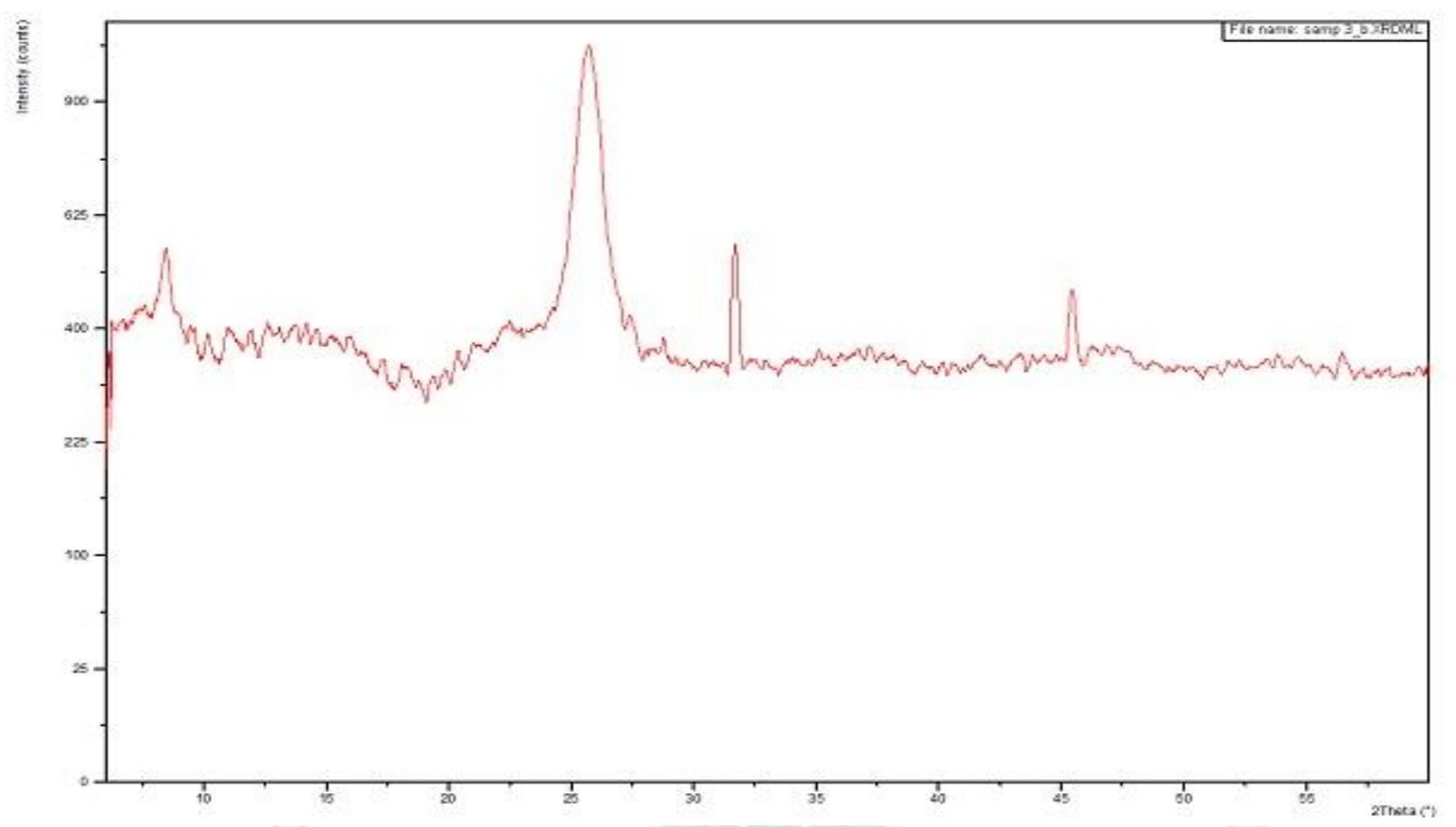

Figure 8: Sample- XRD of NTZ pure drug

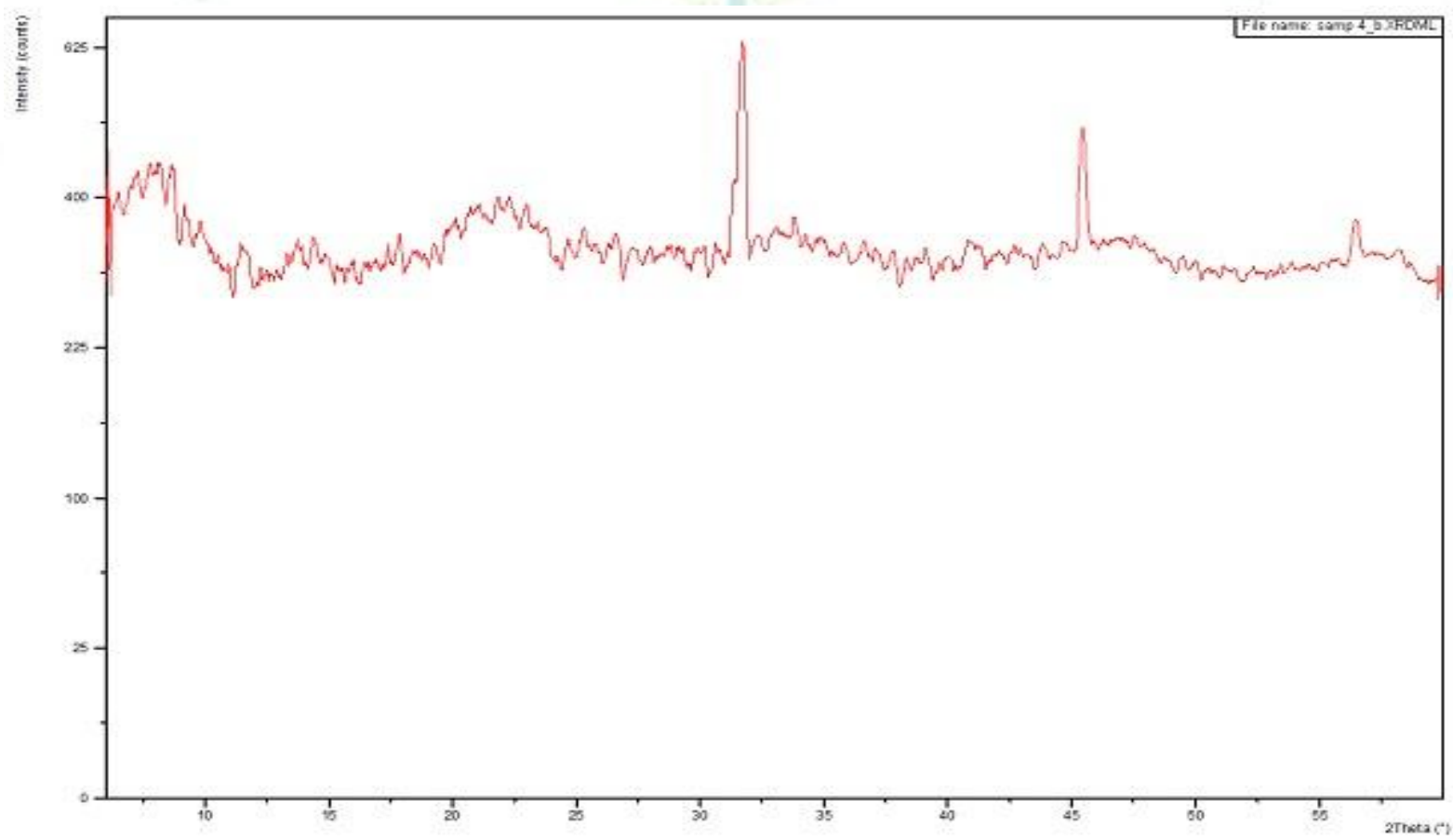

Figure 9: Sample: XRD optimized formulation (F9) of NTZ

\section{Differential scanning colorimetery (DSC)}

DSC provides information about all physical properties of sample as Crystalline or Amorphous nature and demonstrates the possible interaction between Drug and other Polymers. The thermal behavior of Nitazoxanide and physical mixture of drug \& polymers are shown in (Figure No. 10 and 11 ), according to thermogram, Nitazoxanide produced sharp Endothermic peak at $197.5^{\circ} \mathrm{C}$ which conformed crystalline form of the drug. DSC curves of the drug and Physical mixture of drug \& polymers Exhibited an Endothermic peaks at $201.5^{\circ} \mathrm{C}$, which has been attributed to the evaporation of water. The thermogram of the physical mixture of Drug and Polymers showed that there was no interaction between drug and polymers. 


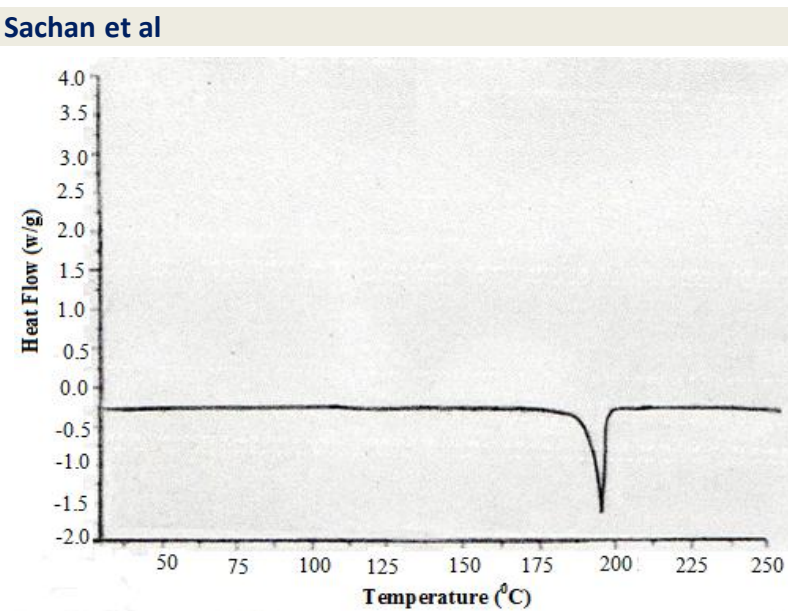

Figure 10: DSC Spectra of pure drug Nitazoxanide

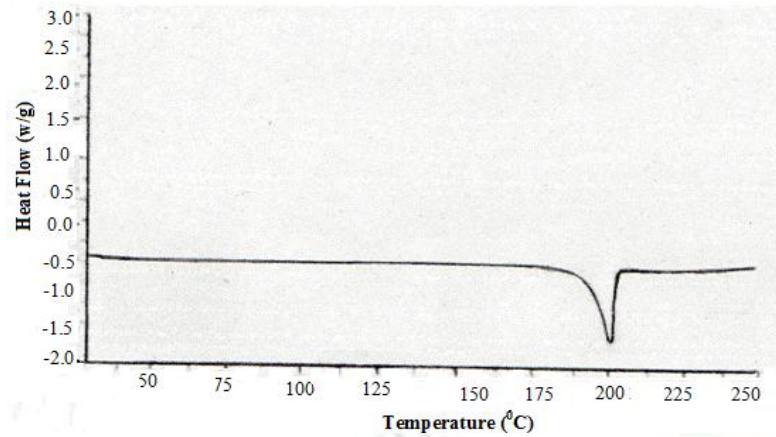

Figure 11: DSC Spectra for physical mixture of pure drug Nitazoxanide +Carbopol 934+Ethyl Cellulose + Sodium Alginate

Mucoadhesion property of optimized formulation of microspheres of Nitazoxanide

The mucoadhesive property of microspheres was evaluated by an in vitro adhesion testing method known as wash-off method in phosphate buffer $\mathrm{pH}$ 7.4.
Journal of Drug Delivery \& Therapeutics. 2018; 8(5):190-199

\begin{tabular}{|c|c|c|}
\hline F.code & $\begin{array}{c}\% \text { mucoadhesion } \\
\mathbf{\pm S . D .}\end{array}$ & $\begin{array}{c}\% \text { Cummulative } \\
\text { release } \pm \text { S.D. }\end{array}$ \\
\hline F1 & $84 \pm 1.45$ & $65.81 \pm 1.42$ \\
\hline F2 & $90 \pm 1.24$ & $73.31 \pm 1.35$ \\
\hline F3 & $70 \pm 1.35$ & $56.81 \pm 1.21$ \\
\hline F4 & $85 \pm 1.65$ & $75.18 \pm 1.12$ \\
\hline F5 & $45 \pm 1.75$ & $80.06 \pm 1.15$ \\
\hline F6 & $78 \pm 1.85$ & $68.44 \pm 1.28$ \\
\hline F7 & $90 \pm 1.65$ & $58.31 \pm 1.45$ \\
\hline F8 & $93 \pm 1.75$ & $69.94 \pm 1.38$ \\
\hline F9 & $95 \pm 1.23$ & $50.25 \pm 1.21$ \\
\hline
\end{tabular}

\section{Invitro Studies}

The prepared microspheres of Nitazoxanide were placed in each of the six basket dissolution apparatus. The assembly was maintained at a temperature of $37^{\circ} \mathrm{C}$ in phosphate buffer, $\mathrm{pH}$ 7.4. Samples were withdrawn at definite time intervals and replaced by equal volume of fresh medium. The absorbance of samples was measured from UV spectrophotometer. Concentration and \% cumulative release of drug from the formulation was then calculated ${ }^{56-57}$.

Dissolution profile revealed that after $10 \mathrm{hr}$. Formulation F1-F9 released $65.81 \%, 73.31 \%, 56.81 \%$, $75.18 \%, 80.06 \%, 68.44 \%, 58.31 \%, 69.94 \%$ and $50.25 \%$ drug respectively. The reason behind the lesser drug release of F3, F7, F8 and F9 in comparison to F1, F2, F4, F5, and F6 might be the use of high concentration of Carbopol-934, Ethyl cellulose.

Formulations (F9) showed lesser drug release than (F5) because higher the polymer concentration lower the drug release where as in case of F5 formulation the polymer conc. was less so drug release is higher so F9 Formulation showed best result for sustained release.

Table 6: \% Mucoadhesion of optimized formulation of microspheres of Nitazoxanide

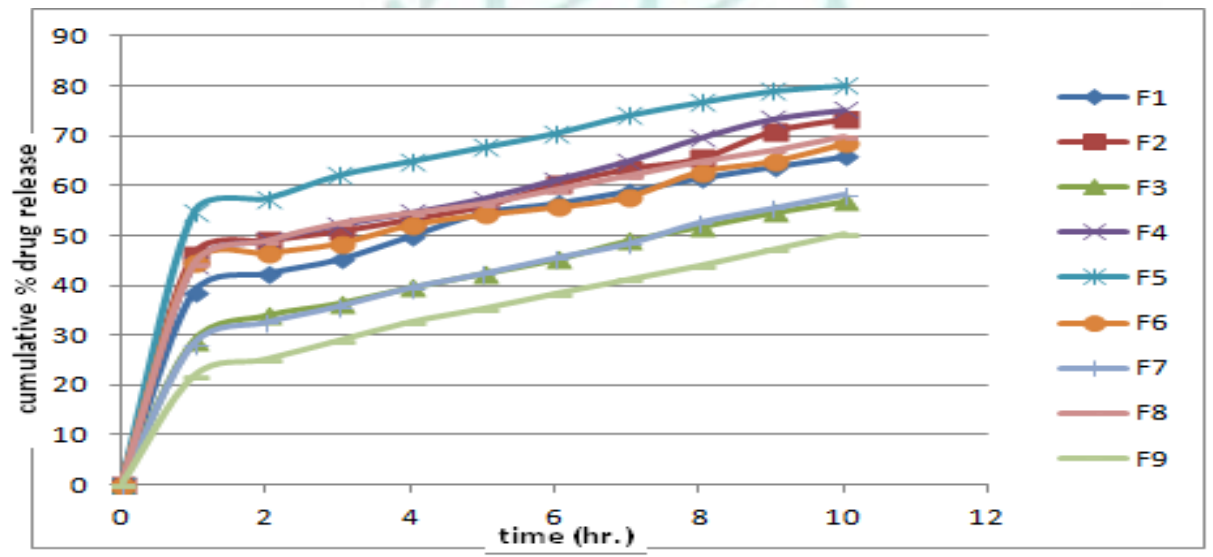

Figure 12: In vitro release profile of Microspheres of Nitazoxanide.

\section{Statistical Analysis}

Factorial design was used to select the factors displaying the most effects on the microspheres properties. $3^{2}$ full factorial design, 2-factor, 3-level.The two obtained factors were carbopol-934 conc. (X1) \& ethyl cellulose conc. (X2) which is in dependent variables \& \% mucoadhesion, in vitro release, \% drug entrapment which is dependent variables. 
Table 7:Two- way ANOVA of Microspheres of Nitazoxanide

\begin{tabular}{|c|c|c|c|c|c|}
\hline Source of Variation & SS & Df & MS & F & P value Prob.> F \\
\hline Model & 858.76 & 3 & 286.25 & 285.18 & 0.0128 Significant \\
\hline A-A & 300.31 & 1 & 300.31 & 21.64 & 0.0288 \\
\hline B-B & 729.59 & 1 & 729.59 & 6.43 & 0.0022 \\
\hline A-B & 180.37 & 1 & 180.37 & 6.75 & 0.0749 \\
\hline Pure error & 400.37 & 9 & 44.49 & 17.82 & \\
\hline Cor total & 1259.13 & 12 & & 4.05 & \\
\hline
\end{tabular}

The Model F-value of 6.43 implies the model is significant. There is only a $1.28 \%$ chance that a "Model F-Value" this large could occur due to noise. Values of "Prob > F" less than 0.0500 indicate model terms are significant.

\section{Stability studies}

Before storage- Drug Content- 25.65 \pm 0.10 , \% Cummulative release- $50.25 \pm 0.12$

Table 8: Stability Analysis of Optimized Formulation F9

Date in- 04/04/2014, Storage Condition- $40^{\circ}$ C, 75\% RH, Packaging- Glass Vials

\begin{tabular}{|c|c|c|c|c|}
\hline $\begin{array}{l}\text { Sampling } \\
\text { interval }\end{array}$ & One week & Two week & Three week & Four week \\
\hline Date & $10 / 04 / 20114$ & $17 / 04 / 2014$ & $24 / 04 / 2014$ & $01 / 05 / 2014$ \\
\hline \multicolumn{5}{|l|}{$\begin{array}{l}\text { Evaluation } \\
\text { parameters }\end{array}$} \\
\hline $\begin{array}{l}\text { Drug content } \\
\text { (mg) }\end{array}$ & $25.09 \pm 0.15$ & $24.89 \pm 0.11$ & $23.95 \pm 0.05$ & $22.98 \pm 0.07$ \\
\hline $\begin{array}{l}\text { \%cumulative } \\
\text { release }\end{array}$ & $50.02 \pm 0.13$ & $49.97 \pm 0.11$ & $48.88 \pm 0.10$ & $47.99 \pm 0.12$ \\
\hline
\end{tabular}

\section{CONCLUSION}

Nitazoxanide loaded Alginate microspheres were successfully prepared by Ionotropic gelation technique. The micromeritic study of microspheres suggests that on formulation of microsphere from pure drug the flow behavior of drug was improved. From the SEM of microspheres it was evident that the microspheres were spherical in shape with smooth surface. The mean particle size of microsphere was found in the range of $580.75 \mu \mathrm{m}$ to $729.94 \mu \mathrm{m}$. A systemic study using a $3^{2}$ Factorial design was done. The independent variables had significant influence on dependent variables. Concentration of polymer ratio influence drug release profile \& entrapment efficiency of microspheres. As the polymer concentration increases, \% drug release decreases whereas the entrapment efficiency increases. All the formulation followed first order release kinetics. The Formulation $\mathrm{F}_{9}$ showed maximum entrapment efficiency of $85.50 \%$ and $50.25 \%$ of control drug release up to $10 \mathrm{hr}$. The microspheres exhibited good mucoadhesive property in the in vitro wash off test and also showed high percentage drug entrapment efficiency. Formulation $\mathrm{F}_{9}$ microspheres were selected as best formulation for preparation of sustained drug delivery system. The data obtained thus suggest that mucoadhesive microspheres can be successfully designed for sustained delivery of Nitazoxanide and to improve patient compliance.

\section{REFERENCES}

1. Adhikari L, Sahu S, Development and validation of Spectrophotometric and Calorimetric Method for determination of Nitazoxanide Tablet dosage form, Int.jour.of ChemTech Research, 2011; 3:131-135.

2. Bhowmik D, Gopinath H, A Review on Control Release Drug Delivery System. The Pharma Innovation, 2012; 1:25-26.

3. Betram G, Katzung, Susane BM. Basic Clinical pharmacology. $11^{\text {th }}$ ed. Tata Mc Graw Hill publication; 2010. P. 918.

4. Bhale S, Patankar RD, RP HPLC Development and validation of Nitazoxanid in Tablet dosage form, International Journal of Pharmacy and Pharmaceutical Sciences, 2011;3(3):71-73.

5. Kappor D, Patel M, Vyas R, Lad C, Tyagi B. A review on microsponge drug delivery system. Journal of Drug Delivery and Therapeutics, 2014; 4(5):29-35. https://doi.org/10.22270/jddt.v4i5.978

6. Deshmukh VN, Jadhav JK, "Formulation, Optimization and Evaluation of Controlled Release Alginate Microspheres Using Synergy Gum Blends" Research J. Pharm. and Tech, 2009; 2:324328.

7. Desh P, MM, Soni CS, UV Spectrophotometric estimation of NTZ in Tablet dosages form, Research journal of pharmacy and technology, 2011; 4:1714.

8. Dhakar RC, Maurya SD, Aggarawal S, Kumar G, Tilak VK, Design and evaluation of SRM Microspheres of Metformin Hydrochloride, International Journal of Comperhensive Pharmacy 2010; 1(1): 1-5.

9. Deshmukh T, Deshmukh V, "Formulation and Evaluation of Mucoadhesive Microspheres of Ziprasidone Hydrochloride for Oral Controlled Release" Current Pharm Research, 2012; 2(2):497-502. 
10. Dusane A, Rattilal, A Review on Sustained release technology, International journal of research in Ayurveda \& pharmacy, 2011; 12:1708.

11. Garg A, Upadhyay P, Mucoadhesive microspheres review, Asian Journal of Pharmaceutical and Clinical Research, 2012; 5:24-27.

12. Hardenia SS, Jain A, "Formulation and Evaluation of Mucoadhesive Microspheres of Ciprofloxacin, Journal of Advanced Pharmacy Education \& Research, 2011; 1(4):214-224.

13. Jadhav V, Gandhi SV, RP-HPLC Determination of Nitazoxanide in Bulk and Different Tablet Formulations, Eurasian Journal of Analytical Chemistry, 2008; 3:318-323.

14. Jenifer LH, A Review: Current approaches to treatment of gastrointestinal infection Focus NTZ, 2009, 263-275.

15. Khan S, Tiwari T, A Review On Microspheres. World Journal of Pharmacy and Pharmaceutical Sciences, 2012; 1:126-130.

16. Kataria S,Middha A, A Review On Microsphere. International Journal of Research in Pharmacy \& Chemistry, 2011; 1:11861193.

17. Kumar S, Singh J, Design and Characterization of Amoxicillin trihydrate Mucoadhesive Microspheres for Prolonged Gastric retention, International Journal of Pharmaceutical Sciences and Drug Research, 2010; 2(2):112-114.

18. Keerthi TS, Kumar S, "Formulation and evaluation of microspheres of Losartan Potassium using biodegradable natural polymers" International Bulletin of Drug Research, 2012; 1(2):120-131.

19. Kapoor D, Patel R, "Formulation, Optimization and Evaluation of Floating Microspheres of Captopril" Asian Journal of biomedical \&Pharmaceutical Sciences, 2012; 2(9):1-10.

20. Rastogi V, Shukla S, Singh R, Lal N, Yadav P. Microspheres: a promising drug carrier. Journal of Drug Delivery and Therapeutics, 2016; 6(3):18-26. https://doi.org/10.22270/jddt.v6i3.1196

21. Kumar S, Senthil S, Kumar A, Evaluation of Clobazam loaded ionically cross-linked microspheres using Chitosan, Available online at www.pelagiaresearchlibrary.com, 2012; 3(6):616-623

22. Kumar S, Kumar A, "Formulation and Evaluation of Colon Targeted Drug Delivery of an Anti-Amoebic Drug" International Journal of Pharmaceutical Innovations, 2012; 2(2):138-143.

23. Lachman L, Lieberman HA, Kanig JL. The theory and practice of industrial pharmacy. $3^{\text {rd }}$ ed. Mumbai: Verghese Publishing House; 1991. P. 254 -255.

24. Josephine J, Mehul RT, "Formulation and In Vitro Evaluation of Floating Microspheres of Anti-Retro Viral Drug as a Gastro retentive Dosage" International Journal of Research in Pharmacy Chemistry, 2011; 1(3):2231-2781.

25. Ahmed MG, Dr. Nagesh, Design of minocycline Hydrochloride Microspheres Loacal delivery in Treatment of Periodontitis, International Journal of Advance Pharmaceutical and Biological Sciences, 2012; 2(4):245-249.

26. Faizi M, Venkatesh MN, "Formulation and Evaluation of Mucoadhesive Microspheres of Amoxicillin Trihydrate by using Eudragit RS 100" International Journal of Chem Tech Research, 2010; 2:466-470

27. Agarwal D, Ranawat M, Chauhan C, Kamble R. Formulation and charecterisation of colon targeted ph dependent microspheres of capecitabine for colorectal cancer. Journal of Drug Delivery and Therapeutics, 2014; 3(6):215-222 https://doi.org/10.22270/jddt.v3i6.747

28. Mehta D, Seth AK, "HPLC Method for Simultaneous estimation of Nitazoxanide in its Tablet dosage form" An International Journal of pharmaceutical Sciences, 2011; 2(4):1-12

29. Khanam N, Sachan AK, Fabrication and evaluation of Propranolol hudrochloride loaded microspheres by Ionic-gelation technique, At www.scholers research library, 2012; 4:815-820.

30. Ali NW, Abbas SS, Validation Stability indicating methods for determination of Nitazoxanide in presence of its degradation products, Journal of pharmaceutical analysis, 2012; 2:105-116.

31. Pavanveena, Chintagunta, Kavitha K, "Formulation and evaluation of Trimetazidine Hydrochloride loaded chitosan microspheres" International Journal of Applied Pharmaceutics, 2010; 2(2):11-15

32. Parashar V, Ahmad D, "Formulation and evaluation of biodegradable microspheres of tinidazole" International Journal of Drug Deliver, 2010; 2:238-241.

33. Senthil PS, Sandu NR, Loganathan S, Formulation and evaluation of Microspheres Containing Imatinib Mesylate using Sodium
Alginate By Chemical Crosslinking Method, Journal of Drug Delivery and Therapeutics, 2012; 2(6):37-40. https://doi.org/10.22270/jddt.v2i6.339

34. Pundir S, Badola A, A Review on Sustained Release matrix Tech \& Recent Advances in matrix drug delivery system, Inter. Jour. of Res. and Tech, 2013; 3:12-13.

35. Patel B, Modi V, Preparation and evaluation of ethyl Cellulose Microspheres Prepared by emulsification-Solvent evaporation method, International Journal for Research in Management and Pharmacy (IJRMP), 2012; 1(1):82-92.

36. Patel RJ, Singh BH, RP HPLC Method for estimation of nitazoxanide in oral suspension formulation, Der Pharma Chemica, 2012; 4(3):1140-1144.

37. Venkatesh PD, Karki R, "Formulation and Evaluation of Microspheres Containing Fluvastatin Sodium" International Journal of Drug Development \& Research, 2012; 4(2).

38. Gupta M, Khunteta A. Optimization of the release kinetics of diltiazem hydrochloride from tableted microspheres. Journal of Drug Delivery and Therapeutics, 2018; 8(1):57-63. https://doi.org/10.22270/jddt.v8i1.1551

39. Rajput S, Agrawal P, A Review on microspheres: methods of preparations and evaluation, World Journal of Pharmacy and Pharmaceutical Sciences, 2012; 1:422-438

40. Rowe CR, Sheskey P. A Hand Book of Pharmaceutical Excipients, $6^{\text {th }}$ ed. Php Pharmaceutical Press; 2010. P .450-858

41. Massa-Reddy RS, Bolmad VB, Metformin $\mathrm{HCl}$ loaded Sod.Alginate Floating Microspheres, Indian Journal of Nove Drug Delivery, 2011, 126-143.

42. Reddy VV, Swaroop AP, Preparation and In-Vitro Evaluation of Lansoprzole mucoadhessive microspheres, An International Journal of Advances in Pharmaceutical Sciences, 2011, 2 .

43. Sharifa S, Ahammad T, RP-HPLC Method development and Validation for Nitazoxanide in Powder for suspension dosage form, International Journal of Pharmaceutical Science and Research, 2013; 4(1):301-305

44. Dehghan S, Aboofazeli R, "Formulation optimization of Nifedipine containing microspheres using factorial design" Affrican journal of pharmacy and pharmacology, 2010; 4:346354

45. Murathoti K.S., Saxena T. Development of mucoadhesive microspheres of levofloxacin for the treatment of $\mathrm{H}$. pylori infection. Journal of Drug Delivery and Therapeutics, 2016; 6(1):34-45. https://doi.org/10.22270/jddt.v6i1.1179

46. Singh A, Sharma R, A Review Article on Sustained release drug delivery system, Int. Res. Journal of Pharmacy, 2012, 3, 22-23.

47. Steve, Bhaskara RD. Standard Hand Book of Biomedica Engineering \& Design. $3^{\text {rd }}$ ed. P. 223-224.

48. Senthil A, Thakkar HR, "Formulation and Evaluation of Mucoadhessive Glipizide Microspheres using Carboxy methyl Cellulose" International Journal of Preclinical and Pharmaceutical Research, 2011; 2(1):45-51.

49. Vyas SP, Khar RK. Targated and Control drug delivery. $4^{\text {th }}$ ed. C.B.S. Publications; 2008. P. 418-454.

50. Steve-1, Bhaskara R. A Standard Hand Book of Biomedical engineering. P. 223-224.

51. Sagostarch SA, Journal of Biosciences and Bioengineering, 2002; 94(6):526-529.

52. Kumar TU, Kumar N, Design and evaluation of aceclofenac microspheres by solvent Evaporation technique, International Journal of Pharmaceutical Sciences Letters, 2013; 3(1):170-172.

53. Jilakara VS, Design and characterization of mucoadhesive microspheres loaded with Metronidazole for colon specific delivery, Current pharma research, 2013; 3:901-910.

54. Prasanth VV, Rawat S, "Formulation and Evaluation of Floating Microspheres of Captopril” International Journal of Research Article Pharmaceutical Innovations, 2013; 3(2):41-52.

55. Wadke DA,Serajuddin A, Jacobson H, Preformulation testing. In Lieberman HA, Lachman L, Schwartz JB, eds. Pharmaceutical Dosage Forms: Tablets. New York: Marcel Dekker: 1989, 1-73.

56. Yadav A, Kumar JD, "Formulation and evaluation of mucoadhesive microspheres of propranolol hydrochloride for sustained drug delivery" Asian Journal of Pharmacy and Medical Science, 2011; 1 (1):1-8

57. Zhang Y, Wei W, Preparation and evaluation of Alginate-chitosan microspheres for oral delivery of insulin, European Journal of Pharmaceutics and Biopharmaceutics, 2011; 77:11-19. 